\title{
Nicotine Measurement
}

National Cancer Institute

\section{Source}

National Cancer Institute. Nicotine Measurement. NCI Thesaurus. Code C147403.

The determination of the amount of nicotine present in a sample. 